\title{
Schema Reliance for Developmental Goals Increases From Early to Late Adulthood: Improvement for the Young, Loss Prevention for the Old
}

\author{
Natalie C. Ebner, Michaela Riediger, and Ulman Lindenberger \\ Max Planck Institute for Human Development
}

\begin{abstract}
People tend to encode and retrieve information in terms of schemata, especially when processing resources are low. This study argues that the life-span schema about developmental goals constitutes a generalized expectation about the life course that associates young adults with growth and older adults with loss prevention. Predictions were that young and older adults possess this schema; that both age groups rely on it when remembering age-associated information about goals; and that this schema reliance is particularly pronounced among older adults, due to age-related difficulties in overcoming schemata. In Experiment 1, participants assigned growth or loss-prevention orientations to young and older faces and adhered to the life-span schema. In Experiment 2, participants were presented young and older faces paired with growth or loss prevention. When later asked to recognize faces and remember goal orientations, participants were more likely to remember young faces with growth and older faces with loss prevention than vice versa. This effect was more pronounced among older adults. Conclusions are that reliance on life-span schemata when remembering developmentally relevant information increases with age.
\end{abstract}

Keywords: schema reliance, goal orientation, face recognition, associative memory, age differences

Schemata can guide how we perceive and remember our environment, helping us to organize information and to reconstruct memory (Anderson \& Pichert, 1978; Bartlett, 1932; Bransford \& Johnson, 1972). A schema is a general knowledge structure, a framework, or a set of beliefs that represents and relates events, percepts, situations, acts, and objects; summarizes redundancy in the world; helps to reconstruct memory; and makes memory for some details more likely than others (Bartlett, 1932; Reisberg, 1996). Despite often being accurate and beneficial in reducing complexity, schemata can also lead to omissions or distortions in representations of originally presented information, biases in encoding and retrieval, and systematic errors (Bartlett, 1932; Fiske \& Neuberg, 1990; Owens, Bower, \& Black, 1979).

Especially when attentional and processing resources are low, which is more likely in late than in early adulthood, people tend to

Natalie C. Ebner, Michaela Riediger, and Ulman Lindenberger, Center for Lifespan Psychology, Max Planck Institute for Human Development, Berlin, Germany.

This research was funded by and conducted at the Max Planck Institute for Human Development. We wish to thank Alexandra M. Freund, Agneta Herlitz, Lars Bäckman, Fredda Blanchard-Fields, and Chris Hertzog for discussions of the studies reported here and Marcia K. Johnson for comments on an earlier version of this article. We thank Julia Delius for improving the English of this article. The assistance of Dulce Erdt, Jan Steinkraus, Anja Böhnke, Valeska Pannier, Ulrike Altmann, Hannah Muscati, and Ruth Fahrland for data collection is much appreciated.

Correspondence concerning this article should be addressed to Natalie C. Ebner, who is now at the Department of Psychology, Yale University, P.O. Box 208205, New Haven, CT 06520-8205. E-mail: natalie.ebner@yale.edu; riediger@mpib-berlin.mpg.de; or seklindenberger@mpib-berlin.mpg.de encode and retrieve information in terms of general, schematic features (Hashtroudi, Johnson, \& Chrosniak, 1989). Indeed, compared with young adults, older adults have been found to rely more on schematic knowledge when trying to retrieve information from long-term memory. For example, they are more likely than young adults to falsely recognize pictures that fall into the same category as previously presented pictures (Koutstaal, Schacter, \& Brenner, 2001) or to incorrectly attribute schematically related statements to speakers associated with that schema (Mather, Johnson, \& De Leonardis, 1999). Neuropsychological correlates suggest that ageassociated increments in schema reliance are related to impaired reflective processing, which critically depends on prefrontal brain areas (Mather \& Johnson, 2003). Individuals with lower performance in tasks related to frontal brain region show, for instance, more difficulty engaging in reflectively demanding tasks and instead rely on simpler heuristic processes. In addition, older adults may rely more strongly on earlier established schemata, as they become less efficient in ignoring irrelevant or invalid information (Hasher \& Zacks, 1988), and they may accept highly accessible responses as being veridical without further attempts at recollection (Jacoby, Bishara, Hessels, \& Toth, 2005). Finally, older adults' greater susceptibility to misinformation and their stronger reliance on preexperimentally established schemata could also reflect their reduced ability to encode and monitor the source of information (Henkel, Johnson, \& De Leonardis, 1998) or their use of inefficient binding mechanisms (Chalfonte \& Johnson, 1996; Shing, Werkle-Bergner, Li, \& Lindenberger, 2008).

In the present study, we were interested in the questions of whether encoding and retrieval of information are influenced by schemata that reflect people's expectations regarding developmental changes across the adult life span and whether the effect of 
these schemata on memory is different for adults of different ages. The present research therefore focused on a specific schema-the life-span schema about developmental goals. We define this schema as a knowledge scaffold that people can use to process and organize developmentally relevant information and that reflects their normative, generalized, and highly consensual expectation about the developmental goals that are predominant in different phases of the life course. Our concept of the life-span schema about developmental goals is distinct from related concepts, such as aging stereotypes, in that it emphasizes the potential effects of schematic knowledge structures on how individuals process agerelevant information.

The idea that developmental goals - that is, individuals' ideas of how they want to shape their own development - change throughout adulthood is grounded in the long-held assumption in developmental psychology that individuals are confronted with an agesequential order of developmental tasks across the life span and that these tasks are reflected in their goals (Erikson, 1968; Havighurst, 1953). This age-related structuring of the life course is based on age-graded, history-graded, and nonnormative factors (Baltes, Cornelius, \& Nesselroade, 1979; Heckhausen, 1999; Neugarten, 1968). In a given historical context, age-graded factors (such as social norms or biological and social clocks) as well as nonnormative events determine individuals' opportunities and the frame of reference for personal development (Freund \& Wrosch, 2001). There is evidence that an age-sequential structure of life tasks is reflected in age-normative expectations. Neugarten, Moore, and Lowe (1968), for instance, showed that there is high consensus between individuals with regard to their ideas of the best age timing of a wide range of developmental tasks (see also Plath \& Ikeda, 1975; Settersten \& Hagestad, 1996).

Furthermore, age-normative conceptions also reflect the systematic age-related changes in the proportion of gains to losses that occur across various functional domains (Baltes, 1987, 1997; Brandtstädter, 1999; Labouvie-Vief, 1981; Staudinger, Marsiske, \& Baltes, 1995): Whereas young adulthood typically provides levels of biological plasticity and environments that offer access to resources and favor acquisition of skills and improvement of functions, older people encounter fewer opportunities to realize growth (Freund \& Baltes, 2000; Freund \& Ebner, 2005; Heckhausen, 1999). Indeed, there is evidence that young and older adults expect more gains than losses in childhood, adolescence, and early adulthood and expect a larger number of losses beginning in middle-age and in late adulthood (Heckhausen, Dixon, \& Baltes, 1989; Heckhausen \& Krueger, 1993).

The changing ratio of resource gains to losses across the adult life span is also reflected on the level of personal goals. Personal goals can be distinguished in terms of their orientation toward growth (i.e., striving for gains and positive outcomes; e.g., "I want to become healthy") as compared with their orientation toward loss prevention (i.e., avoidance of negative states; e.g., "I don't want to become sick"; Ebner, Freund, \& Baltes, 2006; see Elliot \& Harackiewicz, 1996; Emmons, 1996; Higgins, 1997; Markus \& Nurius, 1986, for related concepts). A growth orientation as opposed to an orientation toward loss prevention has been found to prevail in early adulthood (Elliot, Sheldon, \& Church, 1997; Emmons, 1996) and seems to be more functional with respect to task performance and well-being (Coats, Janoff-Bulman, \& Alpert, 1996; Friedman \& Förster, 2001; Roney, Higgins, \& Shah, 1995). With advancing age and as net resources decline, goal orientations increasingly shift toward maintenance and loss prevention, with positive effects on well-being (Ebner et al., 2006; Freund, 2006; Ogilvie, Rose, \& Heppen, 2001).

The first purpose of the present study was to show that these age-related changes in goal orientation are also reflected in people's normative expectations about the developmental goals of adults of different ages, that is, that a life-span schema about developmental goals exists (Experiment 1). The second purpose of the present research was to examine whether adults, especially older adults, rely on this schema when remembering ageassociated information about goals (Experiment 2).

In Experiment 1, participants performed a face-goal orientation categorization task in which they assigned either growth or lossprevention orientations to the faces of young and older individuals. Our hypothesis was that both young and older participants were more likely to assign growth orientations to young faces and lossprevention orientations to older faces than vice versa.

In Experiment 2, participants performed a face-goalorientation memory task in which they were shown faces of young and older individuals that were presented with either growth or loss-prevention orientations. Later, participants were asked to recognize the initially presented faces among equal numbers of distractor faces and to remember which goal orientation had been initially presented with each (correctly or incorrectly) recognized face. We expected participants' memory to be best for faces that were initially encoded with goal orientations consistent with the life-span schema about developmental goals (i.e., young faces combined with growth orientations, and older faces combined with loss-prevention orientations). We also hypothesized that the recall of goal orientations would be influenced by whether the initial association reflected respective age-normative expectations: We expected participants to be more likely to correctly remember growth orientations initially combined with young faces and lossprevention orientations initially combined with older faces. With regard to falsely recognized faces, we hypothesized that participants would be more likely to attribute growth orientations to young faces and loss-prevention orientations to older faces than vice versa. In addition to these general effects, we expected older adults to rely more heavily on the life-span schema when encoding and retrieving new information, reflecting their impairment in forming schema-inconsistent associations and overcoming preexperimentally established schema-consistent ones.

\section{Experiment 1}

\section{Method}

\section{Participants}

Twenty-four young (20-29 years, $M=23.9$ years, $S D=2.6$ ) and 24 older participants ( $71-85$ years, $M=76.6$ years, $S D=$ 3.8) ${ }^{1}$ took part in Experiment 1. Participants were drawn from the participant pool of the Max Planck Institute for Human Development. The sample was stratified by gender and education: Fifty percent of the young and $50 \%$ of the older participants were women, and $54 \%$ of the young and $54 \%$ of the older participants

\footnotetext{
${ }^{1}$ One older male participant did not finish the computer task for time reasons.
} 
had a higher secondary level of education (comparable to 2 years or more of college). Cognitive characteristics were comparable to those of previously published samples. ${ }^{2}$

\section{Procedure, Design, Measures, and Materials}

Overview. Experiment 1 consisted of one test session. Young and older participants were tested in separate sessions. First, participants were informed about the testing procedure and signed a consent form before responding to a short sociodemographic questionnaire and working on the Digit Symbol Substitution Test (Wechsler, 1981). Then, participants rated each of the 160 faces used as experimental stimuli in this study along various dimensions (face-goal-orientation categorization task, described in the following section). At the end of the session, participants were asked to indicate their own current mood on a 3 -point scale $(0=$ sad, $1=$ neutral, $2=$ happy $)$. The session typically took $150 \mathrm{~min}$, including two 5-min breaks about every 45 minutes. All participants were debriefed and received monetary reimbursement.

Face-goal-orientation categorization task. Participants were shown 160 faces, one at a time, on Apple Power Mac G5 1.8-GHz computers (Apple, Inc., Cupertino, CA). The presentation order followed a randomized age- and sex-matched design: Each randomized order was presented to 1 person per age and gender group, resulting in 12 different presentation orders. Across these 12 presentation orders, we controlled for the mean position of each picture in the sequence. Participants rated each face in terms of the depicted person's attractiveness, likeability, distinctiveness, goal orientation, energy, mood, and age (for specific instructions, see Appendix A). Wordings and descriptive information on the ratings of young and older faces for each of the dimensions are summarized in Table 1.

Source and selection of facial stimuli. The faces used in Experiment 1 were taken from the Productive Aging Laboratory (PAL) Face Database (Minear \& Park, 2004). From this larger database, we selected 160 faces (80 young, 80 older, evenly distributed across gender). Selection criteria were that the faces (a) were White, (b) matched the targeted age groups (i.e., belonged to persons that were either between the ages of 18 and 32 years or 70 years and older), (c) did not display any distinctive features, and (d) showed a neutral facial expression. When necessary, we modified the selected pictures by standardizing them with respect to contrast effects, background color, and color of clothes (see Ebner, 2008).

\section{Results}

The percentage of categorizations of growth and lossprevention goal orientations to young and older faces in the two age groups are graphically summarized in Figure 1. To accommodate the hierarchical structure of the data (i.e., ratings of faces nested within participants) and to examine within-person and between-person differences at different levels of analysis simultaneously, we used multilevel random coefficient modeling (MRCM; Nezlek, 2001; Raudenbush \& Bryk, 2001). All analyses pertaining to MRCM were conducted with hierarchical linear and nonlinear modeling (HLM, Version 6; Raudenbush, Bryk, \& Congdon, 2000).
Table 1

Wordings and Descriptive Information About Ratings of Young and Older Faces in the Total Sample in Experiment 1

\begin{tabular}{|c|c|c|c|}
\hline \multirow[b]{2}{*}{ Rating dimensions } & \multicolumn{3}{|c|}{ Total sample } \\
\hline & $\begin{array}{c}\text { All } \\
\text { faces }\end{array}$ & $\begin{array}{l}\text { Young } \\
\text { faces }\end{array}$ & $\begin{array}{l}\text { Older } \\
\text { faces }\end{array}$ \\
\hline \multicolumn{4}{|l|}{ Attractiveness $^{\mathrm{a}}(0-4$ points $)$} \\
\hline$M$ & 1.46 & 1.68 & 1.23 \\
\hline$S D$ & 0.57 & 0.56 & 0.65 \\
\hline \multicolumn{4}{|l|}{ Likeability $^{\mathrm{b}}$ ( $0-4$ points) } \\
\hline$M$ & 1.82 & 1.89 & 1.75 \\
\hline$S D$ & 0.42 & 0.46 & 0.45 \\
\hline \multicolumn{4}{|l|}{ Distinctiveness $^{\mathrm{c}}(0-4$ points $)$} \\
\hline$M$ & 1.85 & 1.86 & 1.83 \\
\hline$S D$ & 0.55 & 0.58 & 0.56 \\
\hline \multicolumn{4}{|c|}{ Goal orientation $^{\mathrm{d}}$ (\% of responses) } \\
\hline \multicolumn{4}{|l|}{ Growth } \\
\hline$M$ & 54.0 & 73.0 & 35.0 \\
\hline$S D$ & 10.2 & 16.0 & 16.3 \\
\hline \multicolumn{4}{|l|}{ Loss prevention } \\
\hline$M$ & 46.0 & 27.0 & 65.0 \\
\hline$S D$ & 10.2 & 16.0 & 16.3 \\
\hline \multicolumn{4}{|l|}{$\operatorname{Energy}^{\mathrm{e}}(0-4$ points $)$} \\
\hline$M$ & 2.14 & 2.26 & 2.02 \\
\hline$S D$ & 0.40 & 0.44 & 0.44 \\
\hline \multicolumn{4}{|l|}{$\operatorname{Mood}^{\mathrm{f}}(\%$ of responses) } \\
\hline \multicolumn{4}{|l|}{$\mathrm{Sad}$} \\
\hline$M$ & 17.0 & 13.0 & 21.0 \\
\hline$S D$ & 8.0 & 7.6 & 10.7 \\
\hline \multicolumn{4}{|l|}{ Neutral } \\
\hline$M$ & 55.0 & 59.0 & 51.0 \\
\hline$S D$ & 13.7 & 15.7 & 14.0 \\
\hline \multicolumn{4}{|l|}{ Happy } \\
\hline$M$ & 28.0 & 28.0 & 28.0 \\
\hline$S D$ & 11.7 & 13.3 & 11.8 \\
\hline \multicolumn{4}{|l|}{$\operatorname{Age}^{\mathrm{g}}(0-7$ points $)$} \\
\hline$M$ & 2.39 & 0.43 & 4.35 \\
\hline$S D$ & 0.30 & 0.23 & 0.51 \\
\hline
\end{tabular}

Note. $\quad$ a Response to question "How attractive is this person?" rated on a scale from 0 (not attractive at all) to 4 (very attractive). ${ }^{\mathrm{b}}$ Response to question "How likeable is this person" rated on a scale from 0 (not likeable at all) to 4 (very likeable). $\quad{ }^{\mathrm{c}}$ Response to question "How distinctive is this person?" rated on a scale from 0 (not distinctive at all) to 4 (very distinctive). ${ }^{\mathrm{d}}$ Response to question "I think this person would like to improve or to prevent loss in functioning" indicated with either 0 (improve i.e., growth) or 1 (prevent losses). ${ }^{\mathrm{e}}$ Response to question "How energetic is this person?" rated on a scale from 0 (not energetic at all) to 4 (very energetic). ${ }^{\mathrm{f}}$ Response to question "What mood is this person in?" indicated with either 0 ( $\mathrm{sad}$ ), 1 (neutral), or 2 (happy). ${ }^{\mathrm{g}}$ Response to question "How old is this person?" indicated with 0 (20-30 years), 1 (30-40 years), 2 (40-50 years), 3 (50-60 years), 4 (60-70 years), 5 (70-80 years), 6 (80-90 years), or 7 (90-100 years).

The categorization of a growth or loss-prevention orientation to a face constituted the dependent variable in the model. At the between-person level, we used age group of participant as a predictor variable to examine whether participants' categorization

\footnotetext{
${ }^{2}$ Young and older participants did not differ in their self-reported current mood. As usually reported in the literature, young and older participants did, however, differ in their processing-speed performance, $F(1,46)=36.6, p<.05, \eta_{\mathrm{p}}^{2}=.44$, with young participants $(M=59.5$, $S D=11.4)$ scoring higher than older participants $(M=40.5, S D=10.4)$.
} 


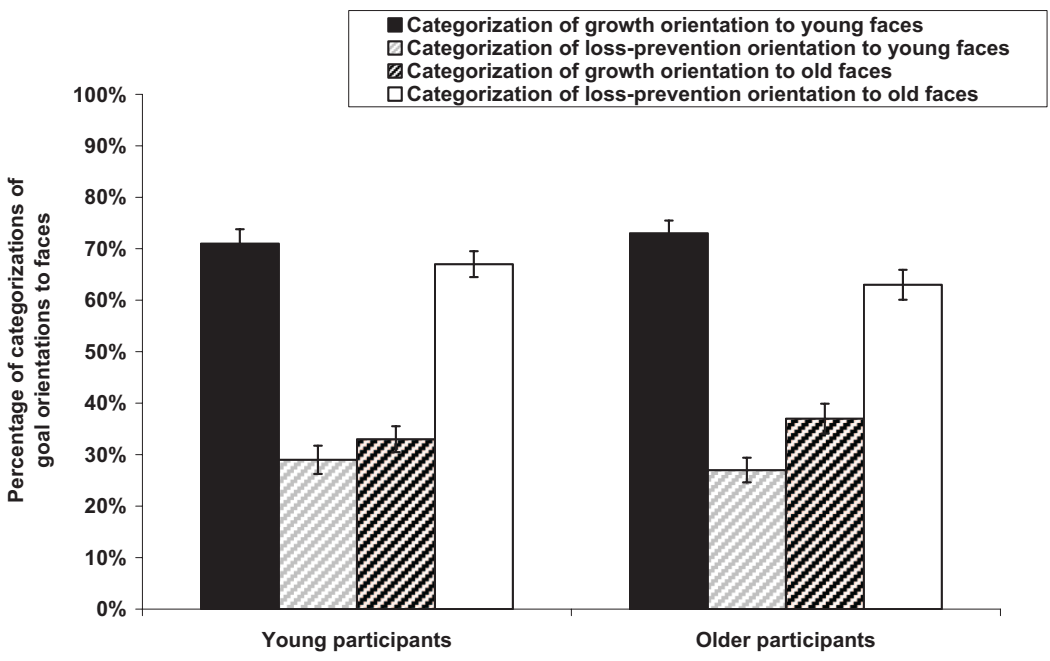

Figure 1. Percentage of categorizations of growth and loss-prevention goal orientations to young and older faces in young and older participants. Error bars represent two standard errors.

of goal orientations to faces varied as a function of the participants' age group. At the within-person level (i.e., the level of individual faces), we introduced age group of face as a predictor variable to examine whether the participants' categorization of goal orientations to faces varied as a function of the age group of the faces. In addition, the cross-level interaction between age group of participant and age group of face was entered into the model to examine age-related differences in the within-person association between the faces' age group and categorization as having either growth or loss-prevention orientation. The response options for the outcome variable were dichotomous $(0=$ improve, $1=$ prevent losses). We therefore conducted a multilevel logistic regression using restricted penalized quasi-likelihood as the method of estimation (see Hox, 2002). The MRCM results for the categorization are presented in Table 2. The top of Table 2 presents the fixed part of the model (i.e., average effect for age group of participant, average effect for age group of face, and cross-level interaction effect for Age Group of Participant $\times$ Age Group of Face). The random effect (i.e., variance component) is presented at the bottom of Table 2 .

The significant random effect of age group of face indicated that there were interperson differences in categorizations of goal orientations to faces. As indicated by the fixed effects, the relative chance of assigning loss-prevention orientation to older faces was almost 7 times the chance of assigning loss prevention to young faces (odds ratio $=6.88, p<.05$ ). The relative chance of assigning growth orientation to young faces, in turn, was almost 7 times the chance of assigning growth to older faces. Young and older participants did not differ in their assignments of goal orientations to faces (odds ratio $=1.07$, $n s)$. This finding is also evident in the results of additional models, tested separately for young and older faces with age group of participant as the predictor of the goal orientation assigned to that face: Young and older participants were equally likely to assign growth or loss-prevention orientations to young faces (odds ratio $=0.89, n s$ ) and older faces (odds ratio $=0.95$, $n s)$.
These results support our assumption that individuals in both age groups classify faces of different ages on the basis of a life-span schema about developmental goals that attributes growth goals primarily to young adults and loss-prevention

Table 2

Categorization of Goal Orientations to Faces as a Function of Age Group of Participant and Age Group of Face: Results of Multilevel Random Coefficient Modeling in Experiment 1

\begin{tabular}{llll}
\hline & \multicolumn{3}{c}{$\begin{array}{c}\text { Categorizations of goal } \\
\text { orientations to faces }\end{array}$} \\
\cline { 2 - 4 } \multicolumn{1}{c}{ Variable } & $\begin{array}{c}\text { All } \\
\text { faces }\end{array}$ & $\begin{array}{c}\text { Young } \\
\text { faces }\end{array}$ & $\begin{array}{c}\text { Older } \\
\text { faces }\end{array}$ \\
\hline $\begin{array}{l}\text { Fixed effects } \\
\text { Intercept }\end{array}$ & $0.32^{*}$ & $0.32^{*}$ & $2.18^{*}$ \\
Age group of participant & 0.89 & 0.89 & 0.95 \\
Age group of face & $6.88^{*}$ & - & - \\
Age Group of Participant $\times$ & 1.07 & - & - \\
$\quad$ Age Group of Face & & & $0.74^{*}$ \\
Random effects & $1.05^{*}$ & $1.02^{*}$ & - \\
$\quad \begin{array}{l}\text { Intercept } \\
\text { Age group of face }\end{array}$ & $2.56^{*}$ & - & \\
\hline
\end{tabular}

Note. Dependent variable, categorization of goal orientation to faces, was coded as 0 (improve) and 1 (prevent losses). Age group of participant was coded as 0 (young participants) and 1 (older participants). Age group of face was coded as 0 (young face) and 1 (older face).

Reported parameter estimates are odds ratios, indicating the ratio of the odds of loss-prevention categorizations in one group (as specified by the independent variables) to the odds of loss-prevention categorizations in another group. An odds ratio of 1 indicates that loss-prevention categorizations were equally likely in both groups. An odds ratio greater than 1 indicates that lossprevention categorizations were more likely in the group coded 1 than in the group coded 0 . An odds ratio less than 1 indicates that the loss-prevention categorizations were less likely in the group coded 1 than in the group coded 0 . Parameter estimates are explained in the text. Dashes indicate not applicable. ${ }^{*} p<.05$. 
goals primarily to older adults. Young and older participants did not differ in their categorizations, suggesting that they do not differ reliably in their life-span schema about age-group differences in goal orientations. This is consistent with the notion of a normative, generalized, and highly consensual expectation about the life course and developmental goals.

\section{Experiment 2}

In Experiment 2, we examined whether both age groups, but especially older adults, rely on the life-span schema about developmental goals when remembering new associations between faces of different ages and goals with different orientations. In doing so, our aim in Experiment 2 was to integrate the findings of Experiment 1 and the evidence of increased schema reliance in older age reported in the literature.

\section{Method}

\section{Participants}

Fifty-nine young (19-31 years, $M=24.7$ years, $S D=3.2)$ and 60 older participants $(69-79$ years, $M=73.5$ years, $S D=2.9$ ) took part in Experiment 2. Participants were recruited through newspaper ads. The sample was approximately stratified by gender and education: Forty-nine percent of the young and $50 \%$ of the older participants were women, and $59 \%$ of the young and $62 \%$ of the older participants had a higher secondary level of education. Physical and cognitive characteristics were comparable to those of previously published samples. $^{3}$

\section{Procedure, Design, Measures, and Materials}

Overview. Experiment 2 comprised two measurement points (T1, T2). For the majority of participants (96\%), T1 and T2 were exactly 1 week apart. ${ }^{4}$ Young and older participants were tested in separate sessions. Participants were first informed about the testing procedure and signed a consent form. After generating their most important personal goals in the domain of cognitive functioning, participants received instructions on how to handle the computer program for the experimental task (i.e., encoding phase, described later), and the computer program provided practice trials. There was time for questions in case participants needed further clarification of the constructs or the task. Then the Spot-a-Word Test (after Lindenberger, Mayr, \& Kliegl, 1993) and the Digit Symbol Substitution Test were administered.

$\mathrm{T} 2$ began with the experimental computer task (i.e., recognition phase, described later). Again, in addition to the experimenter's instruction, the computer program provided practice trials. Participants then completed a computerized version of the PairedAssociate Learning task (after Brehmer, Li, Müller, von Oertzen, \& Lindenberger, 2007). Both sessions typically took 120 min each. Participants were debriefed and received monetary reimbursement.

Generation of personal goals. To trigger participants' own motivational orientation at the beginning of the study, we asked participants to list their three most important goals in the domain of cognitive functioning. To facilitate goal generation, we provided a short explanation of the concept of personal goals, which included sample goal domains and goals and which also introduced the idea of growth and loss-prevention goals (for specific instructions, see Appendix B). Participants generated goals such as "Improve my language skills" or "Counteract memory losses," which clearly suggest that the concepts of growth and lossprevention goals were well understood.

Face-goal-orientation memory task. Stimuli were presented on Apple Power Mac G5 1.8-GHz computers. The face-goalorientation memory task had two phases (see Figure 2; for specific instructions, see Appendix C): an encoding phase (at T1) and a recognition phase (at T2). At encoding, participants were shown 32 pairs of a goal orientation and a person's face. First, one of two goal orientations - growth ("Cognitive functioning: Improve"; original German wording: "Geistige Fähigkeiten: Verbessern") or loss prevention ("Cognitive functioning: Prevent losses"; original German wording: "Geistige Fähigkeiten: Verluste vermeiden")_ was presented. After $1.5 \mathrm{~s}$, a face was shown in addition to the goal orientation. Presented faces belonged to one of two age groups (i.e., between 18 and 32 years or 70 years and older). All faces displayed a neutral facial expression. Four stimuli were presented for each possible combination of Goal Orientation $\times$ Age of Face $\times$ Gender of Face (i.e., growth-young-male, growth-young-female, loss prevention-young-male, loss prevention-young-female, growth-older-male, growth-older-female, loss preventionolder-male, loss prevention-older-female). The face-goalorientation combinations were presented in an age-matched randomized order: Each randomized order was presented to one young and one older participant. To ensure elaboration of the face-goal-orientation association, the computer program asked participants to think of a specific activity with which the presented person might pursue the respective goal and to press a button as soon as they came up with such an activity. ${ }^{5}$ Independent of the button press, the presentation time for each face-goal-orientation combination was fixed to $30 \mathrm{~s}$. Participants were then asked to type in the specific goal-pursuit activity they had come up with (examples of such self-generated goal pursuit activities were "Play a musical instrument," "Take a class in English as a foreign language," "Read books/the newspaper," and "Keep a diary"). After an interstimulus interval of $1.5 \mathrm{~s}$ and the presentation of a fixation

\footnotetext{
${ }^{3}$ Young and older participants neither differed in their self-indicated subjective functioning nor in their self-reported cognitive functioning, both measured by single-item indicators. They did differ, however, in their processing-speed performance, $F(1,117)=111.0, p<.01, \eta_{\mathrm{p}}^{2}=.49$, in that young participants $(M=58.0, S D=10.8)$ scored higher than older participants $(M=39.3, S D=8.4)$. In addition, young participants $(M=$ 22.8, $S D=5.2$ ) did worse in the Spot-a-Word Test, measuring knowledge, than older participants did $(M=29.0, S D=2.9), F(1,117)=65.7, p<$ $.05, \eta_{\mathrm{p}}^{2}=.36$. Finally, there were age-group differences with regard to memory performance in Paired-Associate Learning task, such that young participants $(M=11.9, S D=3.1)$ performed better than older participants $(M=4.4, S D=3.0), F(1,115)=175.1, p<.05, \eta_{\mathrm{p}}^{2}=.60$.

${ }^{4}$ One older male participant was tested after 6 days, 2 older men and 1 older woman were tested after 8 days, and 1 young woman was tested after 9 days.

${ }^{5}$ Post hoc analysis of participants' response times of button presses during encoding to indicate successful self-initiated processing (i.e., generation of specific goal-pursuit activity for the face-goal-orientation association as a direct indicator of association ease) showed that the age groups did not differ with respect to ease of responding to the different face-goal-orientation combinations (Wilks' $\lambda=.98), F(3,115)=27.0, n s, \eta^{2}=.02,1-\beta=.22$.
} 


\section{Encoding phase}

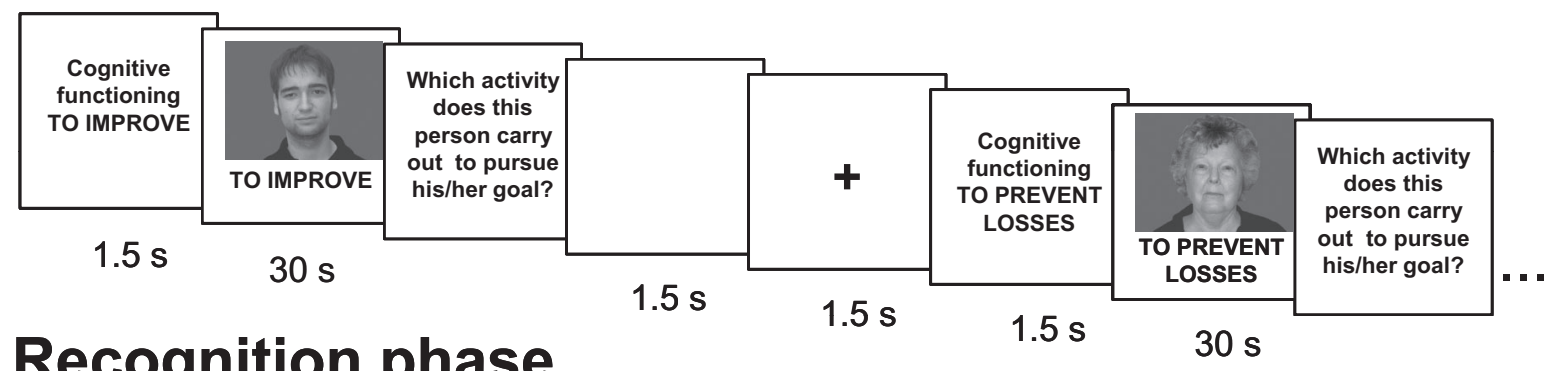

Recognition phase

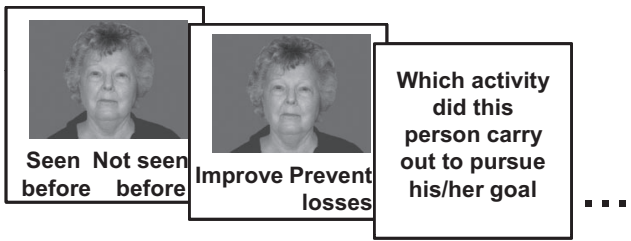

Figure 2. Face-goal orientation memory task. Faces were presented in color on dark gray background.

cross for another $1.5 \mathrm{~s}$, the next goal orientation and face-goalorientation combination appeared on the screen.

At T2, 1 week later, a two-step recognition phase followed. Participants were shown 64 faces displaying neutral facial expressions. Half of the faces had been presented at T1 (target faces); an equal number of male and female faces of young and older individuals were new (distractor faces). Target and distractor faces were counterbalanced across participants. The faces were again presented in an age-matched randomized order; that is, each randomized order of 64 faces was presented to one young and one older participant. For each presented face, participants first made an old-new judgment (face recognition: "Have you seen this person before?" with response options being seen before or not seen before). For each face indicated as being recognized from T1, irrespective of whether this was correct or incorrect, participants were then asked to remember the goal orientation that the face had been presented with at T1 (recall of goal orientation: "What type of goal did this person pursue?" with response options being improve or prevent losses; original German wording: "Verbessern" or "Verluste vermeiden"). Finally, participants were asked to type in the specific goal-pursuit activity for the person they had come up with at T1. Then, after an interstimulus interval of $1.5 \mathrm{~s}$ and the presentation of a fixation cross for $1.5 \mathrm{~s}$, the next face appeared on the screen.

Source and selection of facial stimuli. The faces used in Experiment 2 were a subset of those used in Experiment 1. We used information from participants' ratings in Experiment 1 and selected 64 faces that were sufficiently homogeneous with respect to ratings of attractiveness, likeability, distinctiveness, and mood.

Self-reported expectations about young and older adults' goal orientations. At the end of T2, participants rated the goal orientation of their own and the respective other age group in the domain of cognitive functioning separately along the dimensions of growth ("With their goals in the domain of cognitive functioning, young/older adults would like to improve something") and loss prevention ("With their goals in the domain of cognitive functioning, young/older adults would like to prevent a loss"). Response options ranged from 1 (does not apply at all) to 8 (applies very well).

\section{Results}

First, we present analyses on self-reported expectations about age-group differences in goal orientations. Second, we report results for the face-goal-orientation memory task.

\section{Self-Reported Expectations About Age-Group Differences in Goal Orientations}

We tested whether young and older participants, when asked explicitly, expected growth to be the primary goal orientation in young adulthood and loss prevention to be the primary goal orientation in old age. The results are presented in Figure 3. A repeated measures analysis of variance (ANOVA) on self-reported expectations about goal orientations with age group of participants (young, older) as the between-subjects factor and age-goalorientation combination (young adults-growth, older adultsgrowth, young adults-loss prevention, older adults-loss prevention) as the within-subject factor yielded a significant main effect for the age-goal-orientation combination, Wilks' $\lambda=.45, F(3$, $115)=47.4, p<.05, \eta_{\mathrm{p}}^{2}=.55$, and a significant interaction, Wilks' $\lambda=.84, F(3,115)=7.4, p<.05, \eta_{\mathrm{p}}^{2}=.16$. As predicted, both age groups adhered to a schematic representation about age-group differences in goal orientations: Young and older participants regarded growth as the primary orientation in young adults and loss prevention as the primary orientation in older adults. The only difference that emerged between the age groups was that, in comparison to young participants, older participants expected young adults to have a more pronounced loss-prevention orientation.

The central purpose of Experiment 2 was to investigate whether the life-span schema about developmental goals influences memory for newly formed face-goal-orientation associations. To ad- 


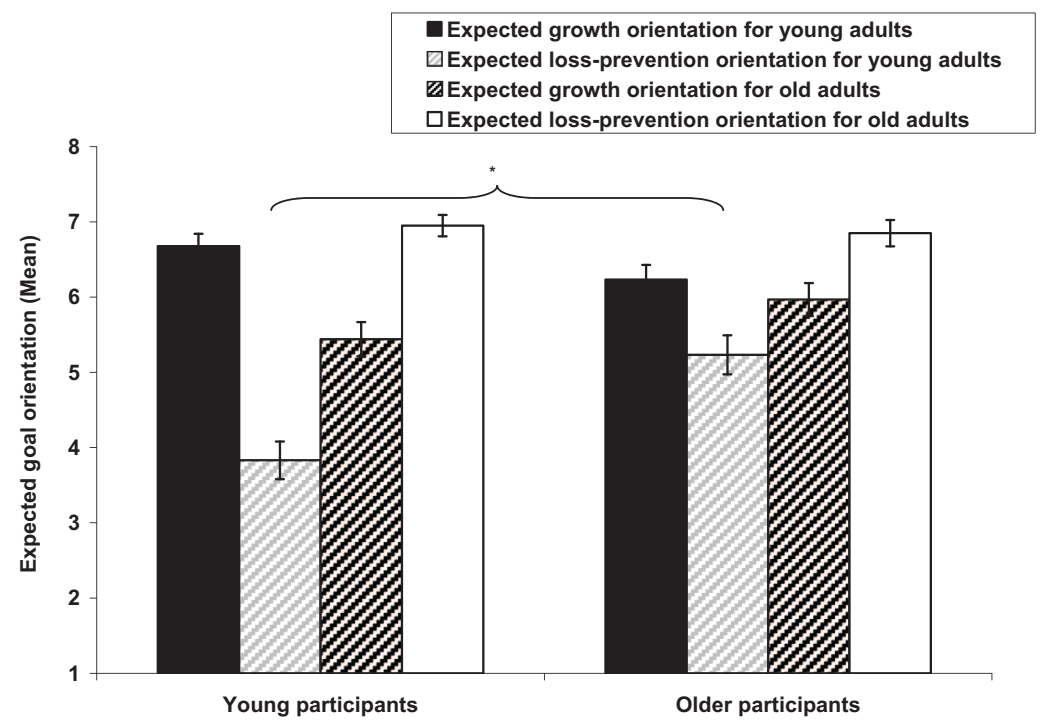

Figure 3. Young and older participants' self-reported expectations about age-group differences in goal orientations. Error bars represent two standard errors. Follow-up univariate comparisons between young and older participants: young adults— growth $(p>.05)$, older adults— growth $(p>.05)$, young adults-loss prevention, $F(1,117)=15.1, p<.01, \eta_{\mathrm{p}}^{2}=.11$, older adults-loss prevention $(p>.05)$. ${ }^{*} p<.05$.

dress this point, we analyzed three aspects of participants' memory performance at T2: (a) their face recognition, (b) their recall of goal orientations for correctly recognized faces (target faces), and (c) their attribution of goal orientations for incorrectly recognized faces (distractor faces).

\section{Memory Performance at T2}

Face recognition memory. At T2, 1 week after initial encoding, participants indicated whether or not each of 64 faces $(32$ targets, 32 distractors) had been presented at T1. We conducted a multivariate analysis of variance (MANOVA) to test for age-group differences in face recognition. The number of correctly recognized faces and number of correctly rejected faces were the dependent variables. Young and older participants differed in their overall face recognition memory performance, Wilks' $\lambda=.60$, $F(2,116)=39.4, p<.01, \eta_{\mathrm{p}}^{2}=.40$. Young participants $(M=$ $26.5, S D=4.7)$ recognized more faces correctly than did older participants $(M=24.6, S D=4.7), F(1,117)=4.86, p<.05$, $\eta_{\mathrm{p}}^{2}=.04$. Furthermore, young participants $(M=29.5, S D=2.7)$ rejected more faces correctly than did older participants $(M=$ 23.7, $S D=4.7) F(1,117)=70.0, p<.01, \eta_{\mathrm{p}}^{2}=.37$.

To then investigate whether young and older participants were more likely to recognize young faces initially combined with growth orientations and older faces initially combined with lossprevention orientations than vice versa, we again used MRCM. The recognition of target faces at $\mathrm{T} 2$ constituted the dependent variable. At the between-person level, we used age group of participant as the predictor variable to examine whether participants' recognition of target faces varied as a function of participants' age group. At the within-person level, we introduced age group of face at $\mathrm{T} 1$ and goal orientation of face at $\mathrm{T} 1$ as predictor variables to examine whether participants' recognition performance varied as a function of faces' age group and faces' goal orientation. In addition, the cross-level interactions-Age Group of Participant $\times$ Age Group of Face, Age Group of Participant $\times$ Goal Orientation of Face, Age Group of Face $\times$ Goal Orientation of Face, and Age Group of Participant $\times$ Age Group of Face $\times$ Goal Orientation of Face (all referring to T1) -were entered to examine age-related differences in the within-person association between age group of face, goal orientation of face, and correct recognition of faces. As the outcome variable was dichotomous $(0=$ missed recognition of target face, $1=$ correct recognition of target face), we again conducted multilevel logistic regressions.

The MRCM results for the recognition of target faces as a function of age group of participant, age group of face, and goal orientation of face are presented in Table 3. The random effects did not reach significance. With respect to the fixed-effects results, the effect for age group of participant (odds ratio $=0.38, p<.05$ ), the effect for goal orientation of face (odds ratio $=0.68, p<.05$ ), and the interaction between Age Group of Participant $\times$ Age Group of Face (odds ratio $=2.86, p<.05$ ) reached significance. To follow up on this significant interaction, we conducted separate analyses for young and older faces. Age group of participant, goal orientation of face, and Age Group of Participant $\times$ Goal Orientation of Face (all at T1) served as predictor variables in these models. Compared with young participants, the older participants' relative chance of recognizing young faces was only 0.4 (odds ratio = $0.40, p<.05)$. It is interesting that there was no age-group difference with respect to older faces (odds ratio $=1.17, n s$ ). In line with our hypotheses, the relative chance of correctly recognizing young faces initially combined with loss-prevention goal orientations was only 0.71 times the chance of correctly recognizing young faces initially combined with growth goal orientations (odds ratio $=0.71, p<.05$ ). However, no such effect of the goal orientation of the face on the correct recognition of faces was found for older faces (odds ratio $=0.82, n s$ ). Finally, the age 
Table 3

Recognition of Target Faces as a Function of Age Group of Participant, Age Group of Face, and Goal Orientation of Face: Results of Multilevel Random Coefficient Modeling in Experiment 2

\begin{tabular}{|c|c|c|c|}
\hline \multirow[b]{2}{*}{ Variable } & \multicolumn{3}{|c|}{ Recognition of target faces } \\
\hline & $\begin{array}{c}\text { All } \\
\text { faces }\end{array}$ & $\begin{array}{l}\text { Young } \\
\text { faces }\end{array}$ & $\begin{array}{l}\text { Older } \\
\text { faces }\end{array}$ \\
\hline \multicolumn{4}{|l|}{ Fixed effects } \\
\hline Intercept & $7.30^{*}$ & $6.96^{*}$ & $6.02^{*}$ \\
\hline Age group of participant & $0.38^{*}$ & $0.40^{*}$ & 1.17 \\
\hline Age group of face & 0.91 & - & - \\
\hline Goal orientation of face & $0.68^{*}$ & $0.71^{*}$ & 0.82 \\
\hline $\begin{array}{l}\text { Age Group of Participant } \times \\
\text { Age Group of Face }\end{array}$ & $2.86^{*}$ & - & - \\
\hline Age Group of Participant $\times$ & & & \\
\hline Goal Orientation of Face & 1.44 & 1.41 & 0.77 \\
\hline Orientation of Face & 1.10 & - & - \\
\hline $\begin{array}{l}\text { Age Group of Participant } \times \\
\text { Age Group of Face } \times\end{array}$ & & & \\
\hline Goal Orientation of Face & 0.56 & - & - \\
\hline \multicolumn{4}{|l|}{ Random effects } \\
\hline Intercept & $0.81^{*}$ & $0.73^{*}$ & $1.29^{*}$ \\
\hline Age group of face & 0.48 & - & - \\
\hline Goal orientation of face & 0.01 & 0.00 & 0.12 \\
\hline Age Group of Face $\times$ Goal & & & \\
\hline Orientation of Face & 0.17 & - & - \\
\hline
\end{tabular}

Note. Dependent variable, recognition of target faces, was coded as 0 (missed recognition of target face) and 1 (correct recognition of target face). Age group of participant was coded as 0 (young participants) and 1 (older participants). Age group of face was coded as 0 (young face) and 1 (older face).

Reported parameter estimates are odds ratios, indicating the ratio of the odds of correct categorizations of target faces in one group (as specified by the independent variables) to the odds of correct categorizations of target faces in another group. An odds ratio of 1 indicates that correct categorizations of target faces were equally likely in both groups. An odds ratio greater than 1 indicates that correct categorizations of target faces were more likely in the group coded 1 than in the group coded 0 . An odds ratio less than 1 indicates that correct categorizations of target faces were less likely in the group coded 1 than in the group coded 0 . Parameter estimates are explained in the text. Dashes indicate not applicable. ${ }^{*} p<.05$.

groups did not differ in their recognition of young (odds ratio $=$ $1.41, n s$ ) or older faces (odds ratio $=0.77, n s$ ) as a function of the faces' goal orientation.

Taken together, the results up to this point partly support our assumption that participants' face-recognition performance was influenced by the combination between age of face and goal orientation at encoding. Young faces that had initially been presented with loss-prevention orientations were less likely to be correctly recognized than young faces that had initially been presented with growth orientations. In contrast to our expectations, however, no differences were found for older faces. Furthermore, young and older participants' face-recognition performance was not differentially influenced by faces' age and goal orientation. However, irrespective of face-goal-orientation combinations at encoding, older participants were worse than young participants at recognizing young faces but did not differ from young participants in recognizing older faces.
Recall of goal orientations for correctly recognized faces. For each face that participants indicated as having recognized from T1, they were also asked to remember the goal orientation with which it had been presented. These responses either referred to (a) faces that participants had correctly recognized as having been presented at T1 (target faces) or (b) faces that participants had falsely indicated as having been presented at T1 (distractor faces). Whereas responses referring to target faces may have been based on actual recognition processes-at least partially and in addition to attribution processes-responses to distractor faces were solely based on participants' attributions of goal orientations to faces.

We begin with MRCM analyses of participants' recall of goal orientations for correctly recognized faces. The recall of goal orientations of target faces at T2 constituted the dependent variable. At the between-person level, we introduced age group of participant as the predictor variable. At the within-person level, we introduced age group of face at T1 and goal orientation of face at $\mathrm{T} 1$ as predictor variables. In addition, we entered the cross-level interactions-Age Group of Participant $\times$ Age Group of Face, Age Group of Participant $\times$ Goal Orientation of Face, Age Group of Face $\times$ Goal Orientation of Face, and Age Group of Participant $\times$ Age Group of Face $\times$ Goal Orientation of Face (all referring to T1) - into the model to examine agerelated differences in the within-person association among age group of face, goal orientation of face, and recognition of goal orientation of faces. Again, as the outcome variable was dichotomous $(0=$ incorrect recall of goal orientation, $1=$ correct recall of goal orientation), we conducted multilevel logistic regressions.

Figure 4 summarizes the MRCM results for these analyses. The random effects of age group of face, goal orientation of face, and Age Group of Face $\times$ Goal Orientation of Face were significant. This indicated that there were interperson differences in recall of goal orientations of target faces. With regard to the fixed-effects results, the effects that reached significance were as follows: age group of participant (odds ratio $=5.24, p<.05$ ); age group of face (odds ratio $=0.43, p<.05$ ); goal orientation of face (odds ratio $=$ $0.45, p<.05$ ); and the interactions between age group of participant and age group of face (odds ratio $=0.07, p<.05$ ), between age group of participant and goal orientation of face (odds ratio $=$ $0.03, p<.05)$, between age group of face and goal orientation of face (odds ratio $=5.50, p<.05$ ), and between age group of participant, age group of face, and goal orientation of face (odds ratio $=152.5, p<.05)$.

To follow up on the significant interactions, we assessed separate models for young and older faces with age group of participant, goal orientation of face, and Age Group of Participant $\times$ Goal Orientation of Face (all at T1) as predictor variables. Table 4 shows that the older participants' relative chance of choosing the correct goal orientation for young faces was more than 5 times the young participants' chance (odds ratio $=5.17, p<.05$ ). Note that young faces paired with growth orientation were more likely to be correctly remembered than young faces paired with lossprevention orientation. Therefore, as will be shown later, this greater likelihood for the older adults to choose the correct goal orientation for young faces reflects their greater schema-induced bias rather than their superior memory. With regard to older target faces, the older participants' relative chance of correctly remem- 


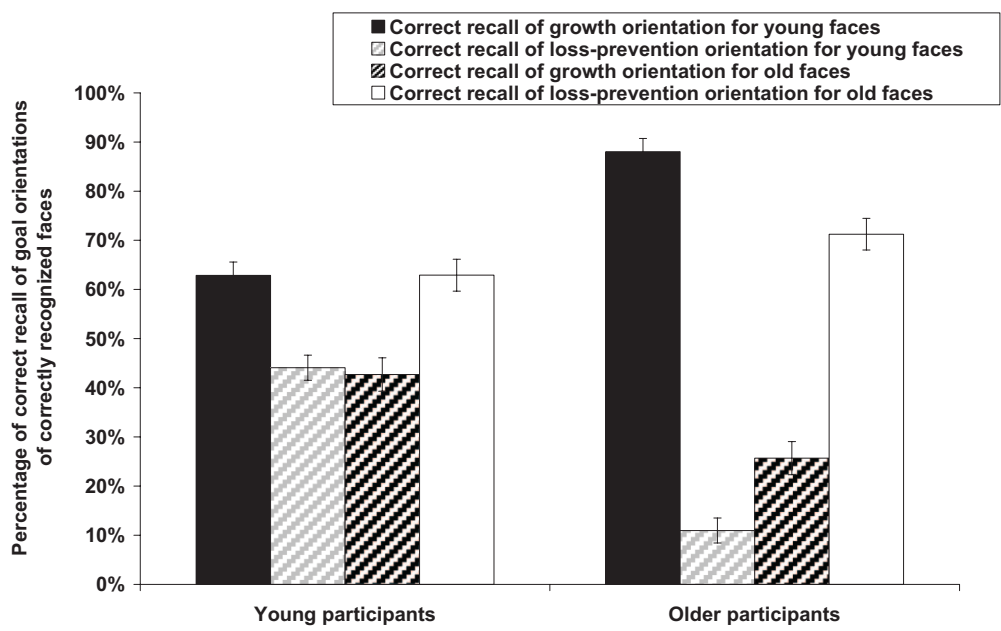

Figure 4. Age-group differences in percentage of correct recall of goal orientations of correctly recognized faces as a function of age of face and goal orientation at encoding. Error bars represent two standard errors.

bering the goal orientation was 0.38 times the young participants' chance (odds ratio $=0.38, p<.05$ ).

The relative chance of correctly recalling the goal orientation of young faces initially encoded with loss prevention was only 0.44 times the chance of correctly remembering the goal orientation of young faces initially encoded with growth (odds ratio $=0.44, p<$ $.05)$. This effect was more pronounced in young than in older participants (odds ratio $=0.03, p<.05$ ). With regard to older faces, the opposite effect was found: The relative chance of correctly recalling the goal orientation of older faces initially encoded with loss prevention was 2.41 times the chance of correctly remembering the goal orientation of older faces initially encoded with growth (odds ratio $=2.41, p<.05$ ). Confirming our expectations, this effect was stronger in older than in young participants (odds ratio $=4.08, p<.05$ ).

In sum, both age groups were more likely to correctly remember the goal orientation for young faces initially presented with growth orientations than the goal orientation for young faces initially presented with loss-prevention orientations. Furthermore, participants in both age groups were more likely to correctly recall the goal orientation of older faces initially presented with loss prevention than older faces initially presented with growth. All of these tendencies were considerably stronger in older adults than in young adults.

Attribution of goal orientations to falsely recognized faces. The analyses up to this point investigated participants' memory for goal orientations of target faces. We now turn to the question of which goal orientations participants attributed to faces that they falsely indicated as having been presented at T1.

Using MRCM, we made attribution of goal orientations to falsely recognized faces the dependent variable. At the betweenperson level, we used age group of participant as the predictor variable to examine whether participants' attribution of goal orientations to distractor faces varied as a function of the participants' age group. At the within-person level, we introduced age group of face as the predictor variable to examine whether participants' attribution of goal orientations to distractor faces varied as a function of age group of the faces themselves. In addition, we entered the cross-level interaction Age Group of Participant $\times$ Age Group of Face to examine age-related differences in the withinperson association between age group of face and attribution of goal orientations to distracter faces. ${ }^{6}$ The outcome variable was again dichotomous $(0=$ improve, $1=$ prevent losses $)$, and we conducted a multilevel logistic regression.

Table 5 summarizes the results. The significant random effect of age group of face indicated that there were interperson differences in attributions of goal orientations to distractor faces. The fixedeffects results show that the relative chance that older participants attributed loss-prevention orientations to distractor faces was only 0.18 times the young participants' chance (odds ratio $=0.18, p<$ $.05)$. Furthermore, the analysis showed that the relative chance that participants attributed loss-prevention orientations to older faces was almost 3 times the chance they attributed loss-prevention orientations to young faces (odds ratio $=2.98, p<.05$ ). Furthermore, the interaction Age Group of Participant $\times$ Age Group of Face again reached significance (odds ratio $=6.05, p<.05$ ). Separate follow-up models for young and older faces with age group of participant as the predictor variable showed that young and older participants differed in terms of their attributions of goal orientations to young distractor faces: Older participants' relative chance of attributing loss-prevention orientations to young faces was only 0.18 times the chance of young participants attributing loss-prevention orientations to young faces (odds ratio $=0.18, p<$ $.05)$. With regard to older faces, the two age groups were equally likely to attribute growth or loss-prevention orientations (odds ratio $=1.09, n s)$.

\footnotetext{
${ }^{6}$ Eleven young participants and 1 older participant did not falsely recognize distractor faces as target faces. Consequently, due to the two-step recognition procedure, these 12 participants had "logically missing data" for the attribution of goal orientations to distractor faces and were excluded from the respective analyses. This resulted in a reduced sample size of 107 $\left(n_{\text {young }}=48 ; n_{\text {older }}=59\right)$.
} 
Table 4

Recall of Goal Orientations of Target Faces as a Function of Age Group of Participant, Age Group of Face, and Goal Orientation of Face: Results of Multilevel Random Coefficient Modeling in Experiment 2

\begin{tabular}{|c|c|c|c|}
\hline \multirow[b]{2}{*}{ Variable } & \multicolumn{3}{|c|}{ Recall of goal orientations } \\
\hline & $\begin{array}{c}\text { All } \\
\text { faces }^{\mathrm{a}}\end{array}$ & $\begin{array}{l}\text { Young } \\
\text { faces }\end{array}$ & $\begin{array}{l}\text { Older } \\
\text { faces }^{\mathrm{a}}\end{array}$ \\
\hline \multicolumn{4}{|l|}{ Fixed effects } \\
\hline Intercept & $1.74^{*}$ & $1.75^{*}$ & $0.77^{*}$ \\
\hline Age group of participant & $5.24^{*}$ & $5.17^{*}$ & $0.38^{*}$ \\
\hline Age group of face & $0.43^{*}$ & - & - \\
\hline Goal orientation of face & $0.45^{*}$ & $0.44^{*}$ & $2.41^{*}$ \\
\hline Age Group of Participant $x$ & & & \\
\hline Age Group of Face & $0.07^{*}$ & - & - \\
\hline Age Group of Participant $x$ & & & \\
\hline Goal Orientation of Face & $0.03^{*}$ & $0.03^{*}$ & $4.08^{*}$ \\
\hline Age Group of Face $\times$ Goal & & & \\
\hline Orientation of Face & $5.50^{*}$ & - & - \\
\hline Age Group of Participant $\times$ & & & \\
\hline Age Group of Face $\times$ & & & \\
\hline Goal Orientation of Face & $152.50^{*}$ & - & - \\
\hline \multicolumn{4}{|l|}{ Random effects } \\
\hline Intercept & $0.76^{*}$ & $0.72^{*}$ & $0.96^{*}$ \\
\hline Age group of face & $2.71^{*}$ & - & - \\
\hline Goal orientation of face & $2.55^{*}$ & $2.35^{*}$ & $3.43^{*}$ \\
\hline \multicolumn{4}{|l|}{ Age Group of Face $\times$ Goal } \\
\hline Orientation of Face & $9.73^{*}$ & - & - \\
\hline
\end{tabular}

Note. Dependent variable, recall of goal orientations of target faces, was coded as 0 (incorrect recall of goal orientation) and 1 (correct recall of goal orientation). Age group of participant was coded as 0 (young participants) and 1 (older participants). Age group of face was coded as 0 (young face) and 1 (older face). Goal orientation of face was coded as 0 (improve) and 1 (prevent losses).

Reported parameter estimates are odds ratios, indicating the ratio of the odds of correct recall of goal orientation in one group (as specified by the independent variables) to the odds of correct recall of goal orientation in another group. An odds ratio of 1 indicates that correct recall of goal orientation was equally likely in both groups. An odds ratio greater than 1 indicates that recall of goal orientation was more likely in the group coded 1 than in the group coded 0 . An odds ratio less than 1 indicates that the recall of goal orientation was less likely in the group coded 1 than in the group coded 0. Parameter estimates are explained in the text. Dashes indicate not applicable.

a Due to "logically missing data," chi-square statistics are based on only $118\left(n_{\text {young }}=59 ; n_{\text {older }}=59\right)$ of 119 units with sufficient data for computation.

${ }^{*} p<.05$.

\section{Discussion}

Integrating cognitive-psychological perspectives on age-group differences in information processing and social-psychological perspectives on age trajectories and developmental goals, we investigated how age-normative conceptions about developmental goals influence memory in norm-conforming ways and in an age-differential manner. Experiment 1 established the existence of a life-span schema about developmental goals in both young and older adults. Experiment 2 showed the influence of such life-span schema on memory for age-associated information about goal orientations and revealed increased schema reliance in older adults compared with young adults.
Young and Older Adults Possess a Life-Span Schema About Developmental Goals: Improvement for the Young, Loss Prevention for the Old

Both young and older adults were more likely to categorize young faces as having growth orientations and older faces as having loss-prevention orientations than vice versa, suggesting that they both possess a life-span schema about developmental goals (Experiment 1). This result is in line with theoretical assumptions (Freund \& Baltes, 2000; Staudinger et al., 1995) and with empirical findings about age-normative expectations about the life course (Heckhausen et al., 1989; Neugarten et al., 1968). It is further supported by the self-reported expectations about agegroup differences in goal orientations obtained in Experiment 2: When asked to indicate their expectations about other young and older adults' goal orientations, both young and older participants regarded growth as the primary orientation in young adults and loss prevention as the primary orientation in older adults. Finally, the presence of a life-span schema about developmental goals is also in accordance with findings of age-group differences in personal goal orientations (Ebner et al., 2006; Ogilvie et al., 2001), with young adults reporting a primary orientation toward growth and older participants reporting an increasingly stronger orienta-

Table 5

Attributions of Goal Orientations to Distractor Faces as a Function of Age Group of Participant and Age Group of Face: Results of Multilevel Random Coefficient Modeling in Experiment 2

\begin{tabular}{llll}
\hline & \multicolumn{3}{c}{ Attribution of goal orientations ${ }^{\mathrm{a}}$} \\
\cline { 2 - 4 } \multicolumn{1}{c}{ Variable } & $\begin{array}{c}\text { All } \\
\text { faces }\end{array}$ & $\begin{array}{c}\text { Young } \\
\text { faces }\end{array}$ & $\begin{array}{c}\text { Older } \\
\text { faces }\end{array}$ \\
\hline Fixed effects & & & \\
$\quad$ Intercept & 0.62 & 0.64 & $1.86^{*}$ \\
Age group of participant & $0.18^{*}$ & $0.18^{*}$ & 1.09 \\
Age group of face & $2.98^{*}$ & - & - \\
$\quad \begin{array}{l}\text { Age Group of Participant } \\
\text { Age Group of Face }\end{array}$ & $6.05^{*}$ & - & - \\
$\begin{array}{l}\text { Random effects } \\
\text { Intercept } \\
\text { Age group of face }\end{array}$ & 0.98 & 0.87 & $0.74^{*}$ \\
\hline
\end{tabular}

Note. Dependent variable, attribution of goal orientations to falsely recognized faces, was coded as 0 (improve) and 1 (prevent losses). Age group of participant was coded as 0 (young participants) and 1 (older participants). Age group of face was coded as 0 (young face) and 1 (older face).

Reported parameter estimates are odds ratios, indicating the ratio of the odds of loss-prevention attributions to falsely recognized faces in one group (as specified by the independent variables) to the odds of loss-prevention attributions to falsely recognized faces in another group. An odds ratio of 1 indicates that loss-prevention attributions were equally likely in both groups. An odds ratio greater than 1 indicates that loss-prevention attributions were more likely in the group coded 1 than in the group coded 0 . An odds ratio less than 1 indicates that the lossprevention attributions were less likely in the group coded 1 than in the group coded 0. Parameter estimates are explained in the text. Dashes indicate not applicable.

${ }^{a}$ Due to "logically missing data," chi-square statistics are based on only 73 $\left(n_{\text {young }}=17 ; n_{\text {older }}=56\right)$ of 107 units with sufficient data for computation. $* p<.05$. 
tion toward loss prevention in their personal goals. ${ }^{7}$ Note, however, that the present investigation did not permit examination of the directionality of the link between personal goal orientation and age-normative expectations about developmental goals.

\section{Life-Span Schema About Developmental Goals Influences Memory for Age-Associated Information About Goal Orientations: Increasing Schema Reliance for Developmental Goals With Age}

In Experiment 2, we found that young and older participants' memory for the face-goal-orientation associations was influenced by their life-span schema about developmental goals. Thus, although the representation of a life-span schema about developmental goals was not different for young and older adults (Experiment 1), such a schema had an age-differential influence on memory for age-associated, goal-related information (Experiment 2).

With respect to participants' face-recognition performance, young faces initially encoded with loss-prevention orientations were less likely to be correctly recognized than young faces initially encoded with growth orientations. It is interesting that young and older adults differed in their face-recognition performance as a function of the age group of the face: Older participants were better at correctly recognizing older faces than at recognizing young faces, irrespective of the goal orientation with which the faces had initially been presented. This finding is consistent with evidence of an own-age bias in face recognition (Anastasi \& Rhodes, 2006; Bäckman, 1991). According to this line of research, adults of different ages have a better memory for faces of their own age group than for faces of other age groups. The effect is often explained by a higher frequency of exposure to, and therefore higher familiarity with, faces in the same as opposed to other age groups (Ebner \& Johnson, in press). Whereas some studies of own-age bias have suggested that the effect is more pronounced in young than in older adults (Bäckman, 1991; Bartlett \& Fulton, 1991), others have found the effect only in older adults (Lamont, Stewart-Williams, \& Podd, 2005). In line with these latter studies and with laboratory crime simulations (Yarmey, 1984), we observed the bias only in older participants. It is possible that older adults primarily focus on stimuli that are most important or salient to them (such as individuals of similar ages) in order to counteract limited cognitive resources or due to that limitation.

Young and older participants' recall of goal orientations for target faces and their attribution of goal orientations for distractor faces were influenced by the life-span schema about developmental goals. Both these effects were more pronounced in older than in young participants. In the case of schema-incongruent face-goalorientation pairs, binding the face to the goal orientation probably required binding of information that is contradictory to the schema and therefore likely required active suppression of the schema. The data clearly show that older adults had more difficulties than young adults in overcoming their age-normative expectations about developmental goals and more strongly relied on the preexperimentally established schema when remembering new facegoal-orientation associations. This finding is in line with the literature on increasing schema reliance with age (Koutstaal et al., 2001; Mather et al., 1999). It is especially interesting (and extends earlier results on this issue), given that the information presented in this study was highly age- and self-relevant, and one could therefore have expected young but also older adults to remember it without having to rely on a preestablished knowledge scaffold.

The literature on age-associated changes in memory offers various (partly interrelated) explanations for increasing schema reliance with age. Dual-process theories of recognition memory, for instance, posit that the ability to remember the past is supported by two processes-recollection (remembering) and familiarity (knowing; Tulving, 1984; Yonelinas, 2002). There is considerable evidence that recollection processes are markedly impaired with age, whereas familiarity shows little or no age-related decline (Daselaar, Fleck, Dobbins, Madden, \& Cabeza, 2006; Mantyla, 1993). As recollection and the ability to overcome habits decrease in old age, older adults are more susceptible to false memories or biases (Jacoby, 1999; Karpel, Hoyer, \& Toglia, 2001; Shing, Werkle-Bergner, Li, \& Lindenberger, 2009) and make attributions on the basis of familiarity (Grady \& Craik, 2000), and familiarity may be more strongly influenced by schematic information than by recollection.

Age-associated failure of inhibitory processes (Hasher \& Zacks, 1988) might also play a role. Older adults might rely more strongly on earlier established schemata, as they become less efficient at ignoring irrelevant or invalid information. They might become more easily "captured" by highly accessible responses and accept them as being veridical without further attempts at recollection (Jacoby et al., 2005), presumably also because of the relative ease of processing and retrieving schema-based information (Hess \& Slaughter, 1990; Rabinowitz, Craik, \& Ackerman, 1982; Yekovich \& Walker, 1986). When unable to recollect past events, older adults may go with the first response that comes to mind, and this response might be schema-consistent rather than schema-inconsistent. Processing differences during both encoding and retrieval may contribute to the observed age changes in schema reliance.

Another explanation draws upon the literatures on source memory and source confusion (Johnson, Hashtroudi, \& Lindsay, 1993; Kliegl \& Lindenberger, 1993; Lindsay \& Johnson, 1989). According to this approach, older adults' greater susceptibility to misinformation and their stronger reliance on preexperimentally established schema reflect their reduced ability to encode and monitor the source of information (Henkel et al., 1998). At least part of older adults' deficient episodic memory performance can also be attributed to their decreased ability to create and retrieve associations among units of information (Naveh-Benjamin, 2000), possibly due to reduced linkage strength (MacKay \& Burke, 1990), decreased effi-

\footnotetext{
${ }^{7}$ This finding was also confirmed in the present study: At the end of Experiment 2, we assessed information on participants' personal goal orientation across their three self-generated goals. A $2 \times 2$ repeated measures ANOVA on subjective ratings of personal goal orientation with age group of participants (young, older) as the between-subjects factor and personal goal orientation (growth, loss prevention) as the within-subject factor yielded a main effect for personal goal orientation, Wilks' $\lambda=.72$, $F(1,117)=46.6, p<.05, \eta_{\mathrm{p}}^{2}=.29$, and an interaction, Wilks' $\lambda=.88$ $F(1,117)=16.7, p<.05, \eta_{\mathrm{p}}^{2}=.16$. As expected, young participants reported a stronger personal goal orientation toward growth $(M=7.0$, $S D=1.0)$ compared with loss prevention $(M=5.0, S D=2.0)$. Older participants did not differ in their personal goal orientation toward growth $(M=6.6, S D=1.4)$ and toward loss prevention $(M=6.1, S D=1.9)$, but they did report a stronger personal goal orientation toward loss prevention than young participants did.
} 
ciency of the simultaneity mechanism (Salthouse, 1996), or inefficient associative-binding mechanisms (Chalfonte \& Johnson, 1996; Li, Naveh-Benjamin, \& Lindenberger, 2005; Shing et al., 2008).

In conclusion, the present research provides converging evidence across different assessment levels (self-report, categorization, or memory), some referring to more conscious and others to less controllable levels. To our knowledge, this is the first study to show that young and older adults possess a life-span schema about developmental goals and that this life-span schema affects memory for ageassociated information about goal orientations-especially so in older individuals. There are likely implications of schema reliance for development goals. In the course of their lives, people build up schemata that help them to reduce the complexity of their environment and that largely correspond with reality. Reliance on the lifespan schema about development goals can be efficient in that it helps people to structure and simplify information and facilitates rapid (and often accurate) processing and integration of new information. In this sense, an accurate schema may be especially beneficial for older adults in that it allows them to counteract age-related cognitive decline that makes encoding and memory for new information difficult. When at odds with reality, however, reliance on the life-span schema leads to mistakes and biases as shown in the present study. The stronger the schema reliance, the less able the person will presumably be to overcome it either during encoding or while remembering. The present study showed the influence of the life-span schema about developmental goals on how information is encoded and retrieved. It remains to be seen whether this schema also has an impact on the type of behavior in which a person actually engages. One could assume that the more pronounced the life-span schema, the more likely a person would also engage in schema-consistent behaviors, which might then render young adults less likely to perceive opportunities for loss prevention and older adults less likely to realize chances for growth and improvement.

\section{References}

Anastasi, J. S., \& Rhodes, M. G. (2006). Evidence for an own-age bias in face recognition. North American Journal of Psychology, 8, 237-252.

Anderson, R. C., \& Pichert, J. W. (1978). Recall of previously unrecallable information following a shift in perspective. Journal of Verbal Learning and Verbal Behavior, 17, 1-12.

Bäckman, L. (1991). Recognition memory across the adult life span: The role of prior knowledge. Memory \& Cognition, 19, 63-71.

Baltes, P. B. (1987). Theoretical propositions of life-span developmental psychology: On the dynamics between growth and decline. Developmental Psychology, 23, 611-626.

Baltes, P. B. (1997). On the incomplete architecture of human ontogeny: Selection, optimization, and compensation as foundation of developmental theory. American Psychologist, 52, 366-380.

Baltes, P. B., Cornelius, S. W., \& Nesselroade, J. R. (1979). Cohort effects in developmental psychology. In J. R. Nesselroade \& P. B. Baltes (Eds.), Longitudinal research in the study of behavior and development (pp. 61-87). New York: Academic Press.

Bartlett, F. C. (1932). Remembering: A study in experimental and social psychology. Cambridge, UK: Cambridge University Press.

Bartlett, J. C., \& Fulton, A. (1991). Familiarity and recognition of faces in old age. Memory \& Cognition, 19, 229-238.

Brandtstädter, J. (1999). The self in action and development: Cultural, biosocial, and ontogenetic bases of intentional self-development. In J. Brandtstädter \& R. M. Lerner (Eds.), Action and self-development: Theory and research through the life span (pp. 37-65). Thousand Oaks, CA: Sage.
Bransford, J. D., \& Johnson, M. K. (1972). Contextual prerequisites for understanding: Some investigations of comprehension and recall. Journal of Verbal Learning and Verbal Behavior, 11, 717-726.

Brehmer, Y., Li, S.-C., Müller, V., Oertzen, T. von, \& Lindenberger, U. (2007). Memory plasticity across the life span: Uncovering children's latent potential. Developmental Psychology, 43, 465-478.

Chalfonte, B. L., \& Johnson, M. K. (1996). Feature memory and binding in young and older adults. Memory \& Cognition, 24, 403-416.

Coats, E. J., Janoff-Bulman, R., \& Alpert, N. (1996). Approach vs. avoidance goals: Differences in self-evaluation and well-being. Personality and Social Psychology Bulletin, 22, 1057-1067.

Daselaar, S. M., Fleck, M. S., Dobbins, I. G., Madden, D. J., \& Cabeza, R. (2006). Effects of healthy aging on hippocampal and rhinal memory functions: An event-related fMRI study. Cerebral Cortex, 16, 1771-1782.

Ebner, N. C. (2008). Age of face matters: Age-group differences in ratings of young and old faces. Behavior Research Methods, 40, 130-136.

Ebner, N. C., Freund, A. M., \& Baltes, P. B. (2006). Developmental changes in personal goal orientation from young to late adulthood: From striving for gains to maintenance and prevention of losses. Psychology and Aging, 21, 664-678.

Ebner, N. C., \& Johnson, M. K. (in press). Young and older emotional faces: Are there age-group differences in expression identification and memory? Emotion.

Elliot, A. J., \& Harackiewicz, J. M. (1996). Approach and avoidance achievement goals and intrinsic motivation: A mediational analysis. Journal of Personality and Social Psychology, 70, 461-475.

Elliot, A. J., Sheldon, K. M., \& Church, M. A. (1997). Avoidance personal goals and subjective well-being. Personality and Social Psychology Bulletin, 23, 915-927.

Emmons, R. A. (1996). Striving and feeling: Personal goals and subjective well-being. In P. M. Gollwitzer \& J. A. Bargh (Eds.), The psychology of action: Linking cognition and motivation to behavior (pp. 313-337). New York: Guilford.

Erikson, E. H. (1968). Identity: Youth and crisis. New York: Norton.

Fiske, S. T., \& Neuberg, S. L. (1990). A continuum of impression formation, from category-based to individuating processes: Influences of information and motivation on attention and interpretation. Advances in Experimental Social Psychology, 23, 1-73.

Freund, A. M. (2006). Age-differential motivational consequences of optimization versus compensation focus in younger and older adults. Psychology and Aging, 21, 240-252.

Freund, A. M., \& Baltes, P. B. (2000). The orchestration of selection, optimization and compensation: An action-theoretical conceptualization of a theory of developmental regulation. In W. J. Perrig \& A. Grob (Eds.), Control of human behavior, mental processes, and consciousness (pp. 35-58). Mahwah, NJ: Erlbaum.

Freund, A. M., \& Ebner, N. C. (2005). The aging self: Shifting from promoting gains to balancing losses. In W. Greve, K. Rothermund, \& D. Wentura (Eds.), The adaptive self: Personal continuity and intentional self-development (pp. 185-202). New York: Hogrefe.

Freund, A. M., \& Wrosch, C. (2001). Self-regulation of normative and non-normative developmental challenges. Human Development, 44, 264-283.

Friedman, R. S., \& Förster, J. (2001). The effects of promotion and prevention cues on creativity. Journal of Personality and Social Psychology, 81, 1001-1013.

Grady, C. L., \& Craik, F. I. M. (2000). Changes in memory processing with age. Current Opinion in Neurobiology, 10, 224-231.

Hasher, L., \& Zacks, R. T. (1988). Working memory, comprehension, and aging: A review and a new view. In G. H. Bower (Ed.), The psychology of learning and motivation: Advances in research and theory (Vol. 22, pp. 193-225). San Diego, CA: Academic Press.

Hashtroudi, S., Johnson, M. K., \& Chrosniak, L. D. (1989). Aging and source monitoring. Psychology and Aging, 4, 106-112. 
Havighurst, R. J. (1953). Human development and education. London: Longmans.

Heckhausen, J. (1999). Developmental regulation in adulthood: Agenormative and sociostructural constraints as adaptive challenges. New York: Cambridge University Press.

Heckhausen, J., Dixon, R. A., \& Baltes, P. B. (1989). Gains and losses in development throughout adulthood as perceived by different adult age groups. Developmental Psychology, 25, 109-121.

Heckhausen, J., \& Krueger, J. (1993). Developmental expectations for the self and most other people: Age grading in three functions of social comparison. Developmental Psychology, 29, 539-548.

Henkel, L. A., Johnson, M. K., \& De Leonardis, D. M. (1998). Aging and source monitoring: Cognitive processes and neuropsychological correlates. Journal of Experimental Psychology: General, 127, 251-268.

Hess, T. M., \& Slaughter, S. J. (1990). Schematic knowledge influences on memory for scene information in young and older adults. Developmental Psychology, 26, 855-865.

Higgins, E. T. (1997). Beyond pleasure and pain. American Psychologist, 52, $1280-1300$.

Hox, J. (2002). Multilevel analysis: Techniques and applications. Mahwah, NJ: Erlbaum.

Jacoby, L. L. (1999). Deceiving the elderly: Effects of accessibility bias in cued-recall performance. Cognitive Neuropsychology, 16, 417-436.

Jacoby, L. L., Bishara, A. J., Hessels, S., \& Toth, J. P. (2005). Aging, subjective experience, and cognitive control: Dramatic false remembering by older adults. Journal of Experimental Psychology: General, 134, 131148.

Johnson, M. K., Hashtroudi, S., \& Lindsay, D. S. (1993). Source monitoring. Psychological Bulletin, 114, 3-28.

Karpel, M. E., Hoyer, W. J., \& Toglia, M. P. (2001). Accuracy and qualities of real and suggested memories: Nonspecific age differences. Journals of Gerontology, Series B: Psychological Sciences and Social Sciences, 56, P103-P110.

Kliegl, R., \& Lindenberger, U. (1993). Modeling intrusions and correct recall in episodic memory: Adult age differences in encoding of list context. Journal of Experimental Psychology: Learning, Memory, and Cognition, 19, 617-637.

Koutstaal, W., Schacter, D. L., \& Brenner, C. (2001). Dual task demands and gist-based false recognition of pictures in younger and older adults. Journal of Memory and Language, 44, 399-426.

Labouvie-Vief, G. (1981). Proactive and reactive aspects of constructivism: Growth and aging in life-span perspective. In R. M. Lerner \& N. A. Busch-Rossnagel (Eds.), Individuals as producers of their development: A life-span perspective (pp. 197-230). New York: Academic Press.

Lamont, A. C., Stewart-Williams, S., \& Podd, J. (2005). Face recognition and aging: Effects of target age and memory load. Memory \& Cognition, 33, 1017-1024.

Li, S.-C., Naveh-Benjamin., M., \& Lindenberger, U. (2005). Aging neuromodulation impairs associative binding: A neurocomputational account. Psychological Science, 16, 445-450.

Lindenberger, U., Mayr, U., \& Kliegl, R. (1993). Speed and intelligence in old age. Psychology and Aging, 8, 207-220.

Lindsay, D. S., \& Johnson, M. K. (1989). The eyewitness suggestibility effect and memory for source. Memory \& Cognition, 17, 349-358.

MacKay, D. G., \& Burke, D. M. (1990). Cognition and aging: A theory of new learning and the use of old connections. In T. M. Hess (Ed.), Aging and cognition: Knowledge organization and utilization (pp. 213-263). Oxford, UK: North-Holland.

Mantyla, T. (1993). Priming effects in prospective memory. Memory, 1, 203-218.

Markus, H., \& Nurius, P. (1986). Possible selves. American Psychologist, 41, 954-969.

Mather, M., \& Johnson, M. K. (2003). Affective review and schema reliance in memory in older and younger adults. American Journal of Psychology, 116, 169-189.

Mather, M., Johnson, M. K., \& De Leonardis, D. M. (1999). Stereotype reliance in source monitoring: Age differences and neuropsychological test correlates. Cognitive Neuropsychology, 16, 437-458.

Minear, M., \& Park, D. C. (2004). A lifespan database of adult facial stimuli. Behavior Research Methods, Instruments, and Computers, 36, 630-633.

Naveh-Benjamin, M. (2000). Adult age differences in memory performance: Tests of an associative deficit hypothesis. Journal of Experimental Psychology: Learning, Memory, and Cognition, 26, 1170-1187.

Neugarten, B. L. (1968). Adult personality: Toward a psychology of the life cycle. In B. L. Neugarten (Ed.), Middle age and aging: A reader in social psychology (pp. 137-147). Chicago: University of Chicago Press.

Neugarten, B. L., Moore, J. W., \& Lowe, J. C. (1968). Age norms, age constraints, and adult socialization. In B. L. Neugarten (Ed.), Middle age and aging (pp. 22-28). Chicago: University of Chicago Press.

Nezlek, J. B. (2001). Multilevel random coefficient analyses of event- and interval-contingent data in social and personality psychology research. Personality and Social Psychology Bulletin, 27, 771-785.

Ogilvie, D. M., Rose, K. M., \& Heppen, J. B. (2001). A comparison of personal project motives in three age groups. Basic and Applied Social Psychology, 23, 207-215.

Owens, J., Bower, G. H., \& Black, J. B. (1979). The "soap opera" effect in story recall. Memory \& Cognition, 7, 185-191.

Plath, D. W., \& Ikeda, K. (1975). After coming of age: Adult awareness of age norms. In T. R. Williams (Ed.), Socialization and communication in primary groups (pp. 107-123). The Hague, The Netherlands: Mouton.

Rabinowitz, J. C., Craik, F. I. M., \& Ackerman, B. P. (1982). A processing resource account of age differences in recall. Canadian Journal of Psychology, 36, 325-344.

Raudenbush, S. W., \& Bryk, A. S. (2001). Hierarchical linear models: Applications and data analysis methods (2nd ed.). Thousand Oaks, CA: Sage.

Raudenbush, S. W., Bryk, A., \& Congdon, R. (2000). HLM 6: Hierarchical linear and nonlinear modeling. Chicago: Scientific Software International.

Reisberg, D. (1996). Cognition: Exploring the science of the mind. New York: Norton.

Roney, C. J. R., Higgins, E. T., \& Shah, J. (1995). Goals and framing: How outcome focus influences motivation and emotion. Personality and Social Psychology Bulletin, 21, 1151-1160.

Salthouse, T. A. (1996). The processing-speed theory of adult age differences in cognition. Psychological Review, 103, 403-428.

Settersten, R. A., Jr., \& Hagestad, G. O. (1996). What's the latest? Cultural age deadlines for family transitions. The Gerontologist, 36, 178-188.

Shing, Y. L., Werkle-Bergner, M., Li, S.-C., \& Lindenberger, U. (2008). Associative and strategic components of episodic memory: A life-span dissociation. Journal of Experimental Psychology: General, 137, 495-513.

Shing, Y. L., Werkle-Bergner, M., Li, S.-C., \& Lindenberger, U. (2009). Committing memory errors with high confidence: Older adults do but children don't. Memory 17, 169-179.

Staudinger, U. M., Marsiske, M., \& Baltes, P. B. (1995). Resilience and reserve capacity in later adulthood: Potentials and limits of development across the life span. In D. C. Cicchetti \& J. Donald (Eds.), Developmental psychopathology (Vol. 2, pp. 801-847). New York: Wiley.

Tulving, E. (1984). Précis of elements of episodic memory. Behavioral and Brain Sciences, 7, 223-268.

Wechsler, D. (1981). Manual for the Wechsler Adult Intelligence ScaleRevised (WAIS-R). New York: Psychological Corporation.

Yarmey, A. D. (1984). Accuracy and credibility of the elderly witness. Canadian Journal on Aging, 3, 79-90.

Yekovich, F. R., \& Walker, C. H. (1986). Retrieval of scripted events. Journal of Memory and Language, 25, 627-644.

Yonelinas, A. P. (2002). The nature of recollection and familiarity: A review of 30 years of research. Journal of Memory and Language, 46, 441-517. 


\section{Appendix A}

\section{Instructions for Face-Goal-Orientation Categorization Task in Experiment 1}

In this task, 160 young and older faces will appear on the computer screen, one at a time. Your task is to respond to a series of questions for each face by button press. A face and a question always appear together. The next face appears as soon as all questions for this face have been answered. There is no "right" or "wrong"; we are interested in your spontaneous, personal opinion.

Appendix B

Instructions for Generation of Personal Goals in Experiment 2

People generally have quite a few ideas about how they want to live their life, what they personally plan, and what they wish, would like, or would not like. Such projects or plans can pertain to various different life domains (e.g., leisure, social relationships, thinking and cognitive functioning). They can pertain to the distant or near future (e.g., "Keep up my memory for names and new things in the next years" or "Learn some Italian in the next couple of days"). They can pertain to everyday matters (e.g., "Solve a crossword puzzle every day") or to more far-reaching issues (e.g., "Live a mentally active life"). Please write down what you wish for personally, what you would like, and what you would not like in the domain of cognitive functioning at present and in the next weeks, months, and years.

Appendix C

Instructions for Face-Goal-Orientation Memory Task in Experiment 2

\section{Encoding Phase}

In this task, faces of different persons will be presented on the screen, one at a time. Each of these persons pursues a goal. Some persons pursue the goal to improve their thinking and their cognitive functioning (e.g., "Learn a new language"). Other persons pursue the goal to prevent losses in their thinking and their cognitive functioning (e.g., "Not to forget names and faces"). Your task is to come up with a specific goal-pursuit activity for each person to help him or her reach his or her goal.

\section{Recognition Phase}

In the last session, we showed you faces of different persons who pursued different goals. This time you will again see pictures of persons, one at a time. Your task is to decide whether you saw that person in the last session. If you signal that you have seen a person before, we will ask you to indicate whether that person pursued the goal to improve his or her thinking and cognitive functioning or the goal to prevent losses in that domain.
Received April 2, 2008

Revision received December 10, 2008

Accepted February 2, 2009 